\title{
Congruent Arc Latarjet with Subscapularis Split in Patients with Shoulder Instability and Hill Sachs Lesions: Functional Outcome at 2-Year Follow-Up
}

\author{
Shiju Majeed $\mathrm{A}^{1 *}$, Richard Jose ${ }^{2}$ and Shrijith $\mathrm{MB}^{3}$ \\ ${ }^{1}$ Department of Orthopedics, Government Medical College, Thiruvananthapuram \\ ${ }^{2}$ Senior Resident. Government Medical College, Thiruvananthapuram, Kerala, India \\ ${ }^{3}$ Senior Resident, All India Institute of Medical Sciences, New Delhi, India
}

*Corresponding author: Shiju Majeed A, Government Medical College, Thiruvananthapuram, Kerala, India.

\begin{abstract}
Introduction: Shoulder dislocations are the most frequent of all dislocations in the body. Recurrence of shoulder dislocations is common in the younger age group with associated Bankart or Hill Sach's lesions. Over 200 procedures have been described in the literature for the treatment of recurrent anterior dislocation of shoulder.

Aim of the study: We attempted to study the functional outcome of Congruent Arc Latarjet procedure in patients with recurrent anterior shoulder dislocations and associated Hill Sach's lesions.

Materials and methods: Rowe score were used to assess the functional outcome in patients 45 patients (39 males and 6 females) with Hill Sach's Lesions were enrolled. The minimum follow-up was 2 years. The mean preoperative Rowe score was 58.5+/-4.2. (Range 51 to 67 IQR=55). All patients had apprehension positivity. 30 patients (66\%) had less than 10 dislocations while $15(33 \%)$ had more than 10 dislocations. Additional lesions present in these patients where soft tissue Bankart in 35 cases, 6 with glenoid bone loss, and 4 had only Bony Bankarts avulsions. Graft union was seen in 38 patients as evidenced by the Xray. Postoperatively, 5 patients (11\%) had excellent results, 34 patients (75\%) had good results, 2 (4\%) had fair results and $4(9 \%)$ had poor results. 4 patients had another episode of dislocation during the follow-up period. 8 patients (18\%) had some degree of apprehension in abducted external rotation. All patients with excellent and good results were able to perform normal daily activities, engage in manual labor and recreational sports activities. There was mean external rotation loss of 20.5 with the arm in adduction and 15.0 with arm in abduction at 90 degrees on comparin g with the normal side.
\end{abstract}

Conclusion: Our study results show that the congruent arc Latarjet procedure with subscapularis split effectively stabilizes anterior shoulder instability in patients with Hill Sach's Lesion.

Level of Evidence: IV: case series

Keywords: Congruent arc Latarjet; Recurrent dislocation shoulder; Hill Sach's Lesion; Anterior shoulder instability; Latarjet procedure

\section{Introduction}

The shoulder, by virtue of its anatomy and biomechanics, is the most unstable and frequently dislocated joints in the body, accounting for nearly $50 \%$ of all dislocations. Anterior dislocations account for about $95 \%$ of recurrent shoulder dislocations [1]. It occurs most frequently in young adults of the age group 20 to 40 years. Of the 200 or so operations described for recurrent anterior instability, there is a gradual shift from open procedures to arthroscopic procedures in the literature. The presence of a Bankarts lesion or its variants (Soft tissue/bony/ALPSA) or a HillSach's Lesion are the predisposing factors in recurrence following traumatic dislocation [1,2]. Bankart's surgery [3] is an anatomical repair in that it attempts to repair the capsulolabral avulsion which is pathognomonic of recurrent dislocations. Bankart's can be done via open or arthroscopic [4-8] approach. However, the arthroscopic 
technique requires proficient arthroscopic skills and there are concerns how best to address bone loss in glenoid and humeral head [4-6]. The other procedures like Latarjet [5,6] and Bristow [9] are non-anatomical and work on the principles of an active muscular sling with coracoid transfer. The Latarjet Procedure [5-9] involves the transfer of the coracoid process along with the attached conjoined tendon to anteroinferior glenoid. It has become popular as it is capable of treating glenoid bone deficiency and an engaging Hill Sachs lesion together. Patte et al [2] proposed the theory of triple locking $[2,10]$. 1. tendinomuscular locking-conjoint tendon and subscapularis muscle acting as sling 2 . Bony locking increased the concavity of the glenoid [3]. Capsular locking as achieved by suture of the coracoacromial stump to capsule as the reasons for stabilizing of shoulder.

Of importance in choosing a particular procedure is the Glenoid track concept [11-14] See (Figure 1.A) and Table 1. For this the width of the inferior glenoid is measured in CT-Scan(D). The width of the glenoid defect is calculated(d). The glenoid track is calculated as $0.83(\mathrm{D}-\mathrm{d})$. The Hill Sach Index (HSI)is calculated as the sum of the width of the Hill Sach lesion and the distance from the lateral border of Hill sach to the medial border of rotator cuff attachment. If HSI is greater than Glenoid track, the hill sach is "off track" or engaging and if HSI is less than Glenoid track, the Hill Sach is "on track" or nonengaging. Engaging Hill Sach Lesion requires remplissage [15] procedure in addition to Capsulolabral repair if done as per Bankarts procedure.

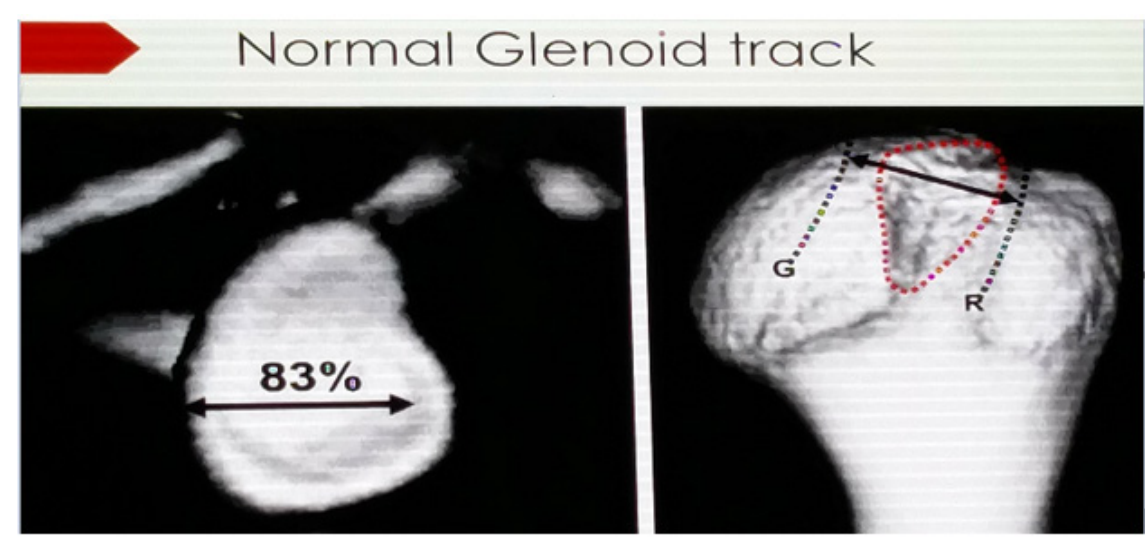

Figure 1: Shows the concept of normal glenoid track.

Table 1: How to determine whether Hill Sach's Lesion is "On track" or "Off Track".

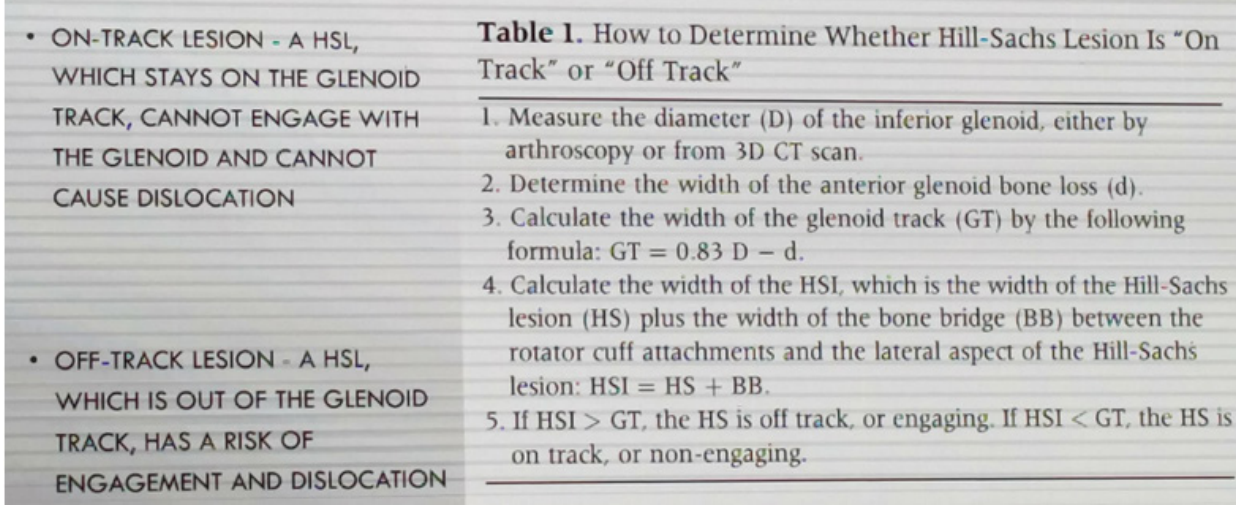

The Latarjet procedure as originally described, termed the Classic Latarjet[5], consists of ostoetomising the coracoid at the elbow formed by its ascending and horizontal pillars, between the coracoclavicular ligaments and the pectoralis minor insertion. The osteotomized coracoid is then transferred to the anterior glenoid and fixated such that its lateral surface is parallel and flush with the articulation (Figure 2A). deBeer's [16] modification to this classic technique is termed the Congruent-Arc Latarjet. This technique involves rotating the coracoid graft $90^{\circ}$ about its longitudinal axis and transferring it such that the inferior surface reconstitutes the glenoid articulation (Figure 2B). This alteration was originally advocated due to the observation that the inferior curvature of the coracoid would result in improved glenohumeral congruity and thus stability. Armitage[17]et al. confirmed this observation through a Computed Tomography anatomy study which found that the radius of curvature of the inferior coracoid surface was not statistically different ( $p>0.05$ ) from the curvature of the native anterior glenoid rim (13.6 vs. $13.8 \mathrm{~mm}$, respectively)

We have been performing Congruent arc Latarjet procedure in our institution for patients with Hill Sach lesion with a soft tissue or bony Bankart as the preferred procedure. Though glenoid track calculation is a logical measurement, its interobserver 
and intraobserver reliability is low[18,19]. Also it has not found consistent use in clinical decision-making setting. Hence the presence of a Hill Sach's Lesion prejudices us to choose a Latarjet procedure. The rate of recurrence following Bankarts is reported to be $15 \%$ in systematic review [20] while in Latarjet it is $7.7 \%$. Patients who have more episodes of dislocations are likely to have engaging Hill Sach's Lesions. The criticism for Latarjet against

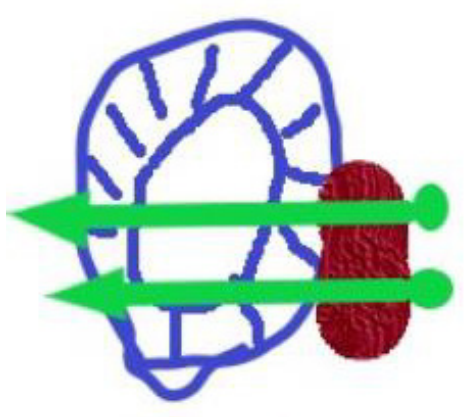

Classic Latarjet
Bankarts is a limitation in shoulder range of movements.

The present study aims to evaluate the clinical outcomes in adult patients who had undergone open Congruent Arc Latarjet procedure in patients with engaging Hill Sach Lesion for recurrent anterior instability of shoulder at our institution. The study was approved by Institutional Ethics committee (HEC no:01/38/2018/ MCT)

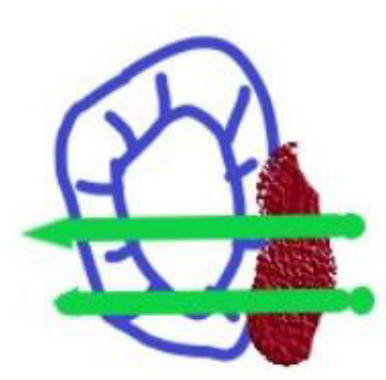

congruent arc Latarjet

Figure 2: Difference between Classic Latarjet and Congruent arc Latarjet Procedure.

\section{Our Technique of Latarjet (Fig 3A,3B,3C,3D)}

The patient is operated in a beach chair position with a sandbag under the shoulder. The arm is draped free. The shoulder is approached through the deltopectoral approach. The coracoid is identified and exposed well from its tip to the glenoid margin. The Pectoralis minor is erased from the medial margin of the glenoid. This step should be done very carefully not to injure the musculocutaneous nerve as its location in the medial aspect of the coracoid can be variable. The conjoint tendon is dissected free and the coracoacromial ligament in the 11 o clock position of the glenoid is severed keeping a stump of $1.5 \mathrm{~cm}$ attached to the coracoid. Using an oscillating saw, the coracoid is divided at it base. Usually, careful planning will help to get 2 to $2.5 \mathrm{~cm}$ of the coracoid. The detached coracoid with attached conjoint tendon and the coracoacromial ligament is carefully brought out of the wound and held with a Kocher forceps. The inferior (concave) side of the coracoid is decorticated to enhance bony union with its glenoid bed. The subscapularis is split transversely along its fibers as necessary for exposure below the equator and the space between capsule and subscapularis is developed with gauze packing. We avoid vertical erasion of subscapularis [21] as it is an important stabilizer of the joint and is important in early recovery and rehabilitation after surgery. The shoulder joint capsule is minimally split near the glenoid margin to get access to the glenoid rim. Carefully placed Hohmann retractors will help us to expose the glenoid rim well. The inferior glenoid rim is freshened with the help of a burr to visualize bleeding from the cancellous bone. The coracoid is transferred to this portion with its lateral border flush with the glenoid rim and provisionally fixed with $2 \mathrm{~K}$ wires. The coracoid is further fixed with two $4.0 \mathrm{~mm}$ cancellous screws with bicortical purchase maintaining parallelism with the glenoid articular surface.

The stump of the coracoacromial ligament is sutured to the shoulder capsule and the split in subscapularis is closed without overtightening with the arm in external rotation. Drains are kept and wound closed. Arm chest bandage is applied for 3 weeks and after that patient was started on pendulum exercises of shoulder and a gradual return of range of motion. Extension and External rotation of the affected shoulder is avoided for six weeks. After that patients progress through exercises to improve the range of motion and strength. Activities involving external rotation are restricted for four months.

All patients who underwent congruent arc Latarjet for recurrent anterior dislocation of shoulder (4 or more episodes) from 2016 to 2018 was included. Patients with psychiatric illness, multidirectional instability were excluded. All patients underwent Xrays (AP internal rotation, axillary views, and CT and MRI shoulder. All patients had a Hill Sach's Lesion in addition to other lesions.

Of the 70 patients who were operated for recurrent dislocations of the shoulder in the period 2016-2018, 45 had hill sach's lesions as evidenced in Xrays and CT Scan. These patients were followed up for at least 2 years. There were 39 males and 6 females in the group. There were 32 patients in the age group $20-30,8$ patients in the age group $30-40$, and 5 patients in the age group above 40 . The minimum follow-up was 2 years. (Range 2 to 3 years) 


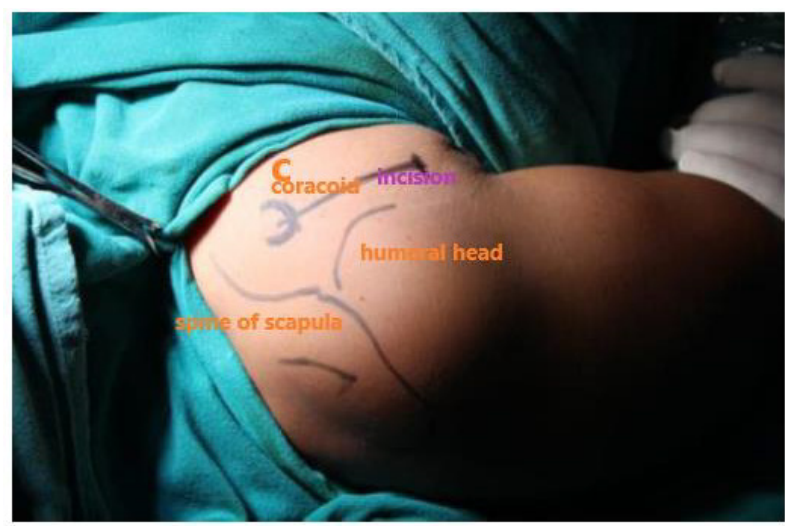

A

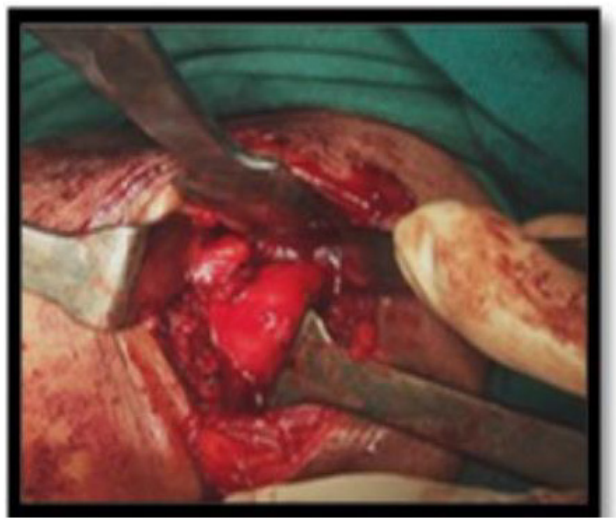

C

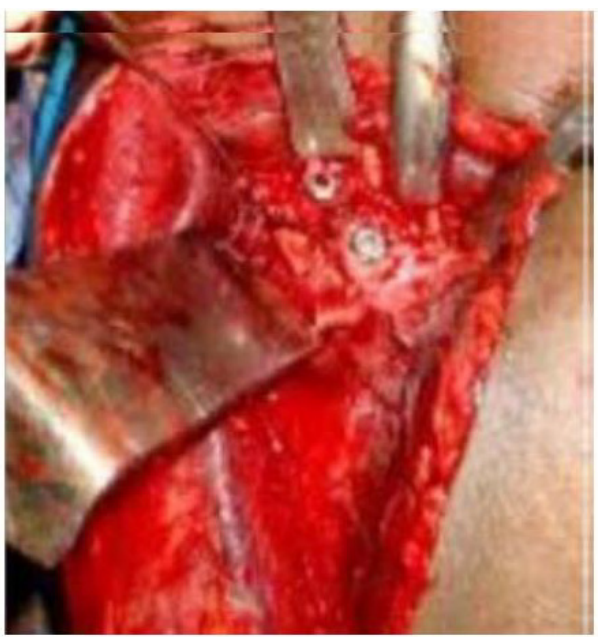

E
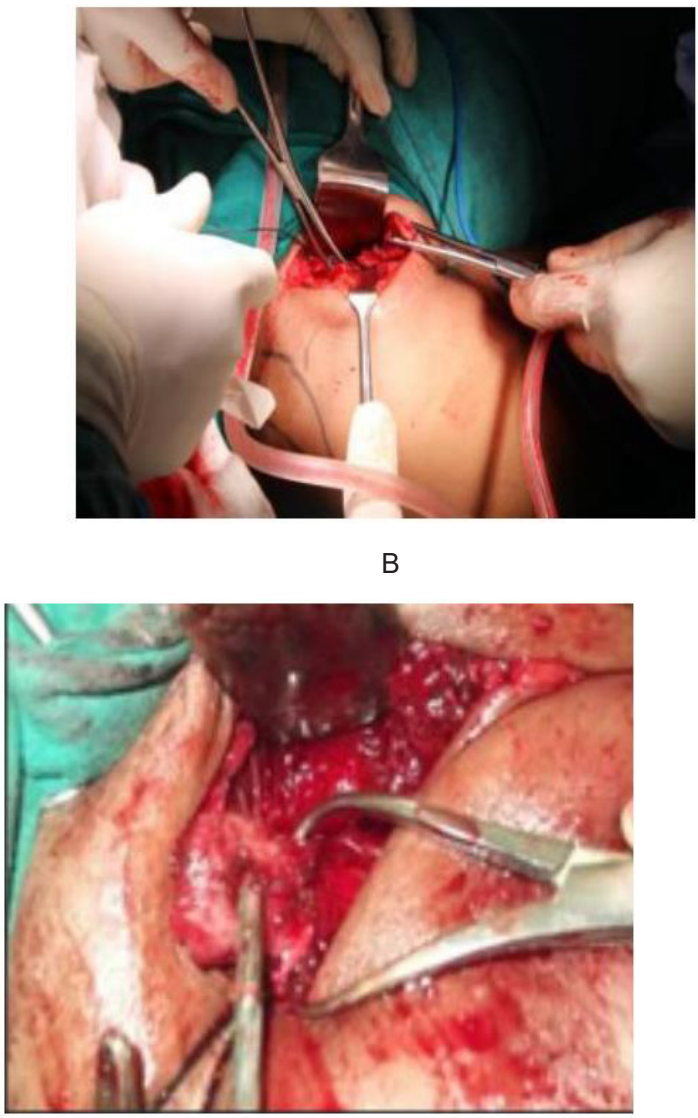

D

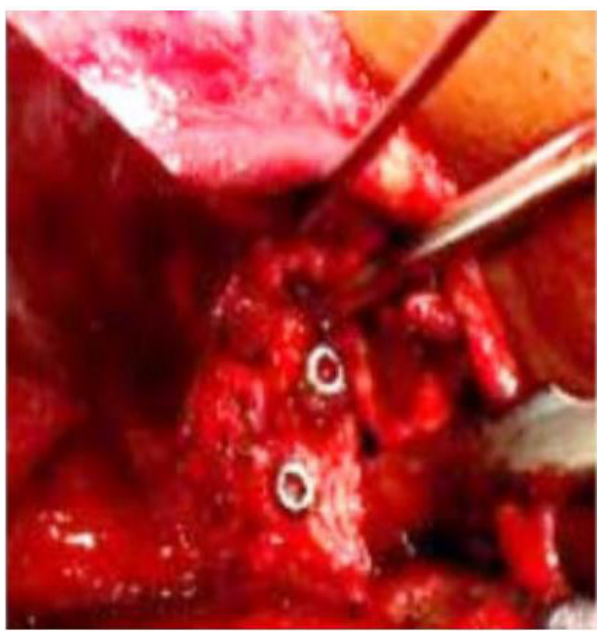

$\mathbf{F}$

Figure 3: Latarjet Steps:

A: Positioning and bony landmarks.

B: Incision and coracoid with conjoint tendon identification.

C: Osteotomized coracoid process.

D: Coracoid fixation after rotating the coracoid 90 degrees so that the anteroinferior surface becomes an extension of the glenoid articular surface.

All 45 patients were right hand dominant, However, recurrent dislocations occurred in the right side in 41 patients and left side in 4 patients. 2 patients had a family history of recurrent shoulder dislocations. 41 patients were of the normal build while 4 were overweight. 15 patients had their first episode while engaging in sports activities.25 patients had their first episode in accidents occurring while engaged in manual labour. 5 patients had their first episode in road traffic accidents, or household falls though they were generally sedentary. 
The mean preoperative Rowe score was 58.5+/-4.2. (Range 51 to $67 \mathrm{IQR}=55$ ) which amounted to poor function of the shoulder. All patients had apprehension positive and anterior drawer positivity at 90 degrees. Patients did not complain of pain, however 22(49\%) of them had complained of vague discomfort.

Recurrent episodes occurred in 6 patients (13\%) while sleeping, $12(26 \%)$ while engaged in throwing sports. The rest of the patients had variable engagements during the time of recurrence. 30 patients (66\%) had less than 10 dislocations while $15(33 \%)$ had more than 10 dislocations. 22patients had their surgery performed within 2 years of the first dislocation.

Additional lesions present in these patients where soft tissue Bankart in 35 cases, 6 with additional glenoid bone loss, and 4 had only Bony Bankarts avulsions (Figure 4-6). Graft union was seen in 38 patients as evidenced by the Xray, 7 patients had doubtful union either fibrous or pseudarthrosis, however they had no clinical significance (Figure 7A-E)

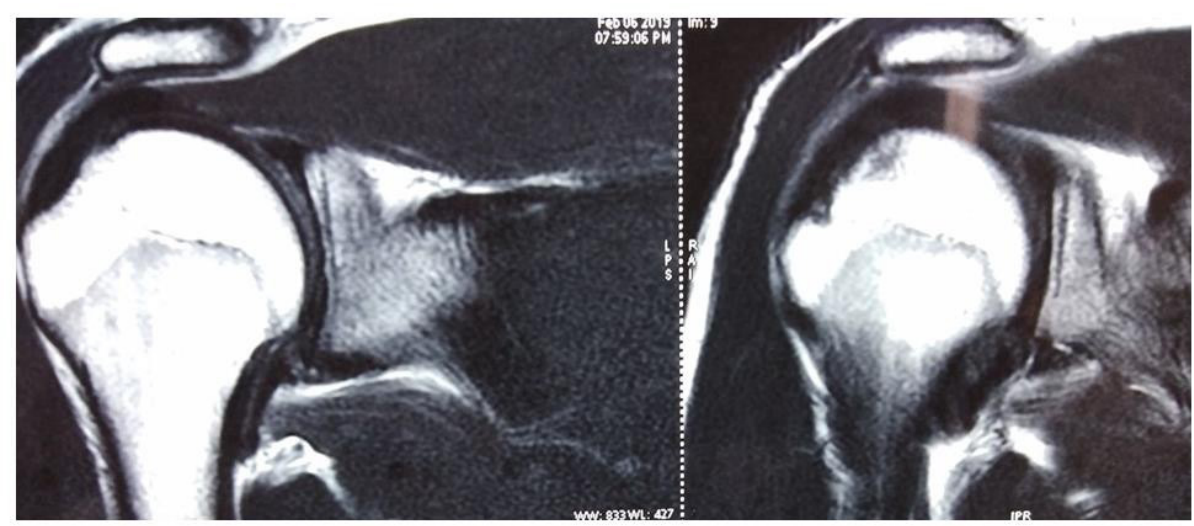

Figure 4: MRI images of Hill Sach and Bankart lesion.

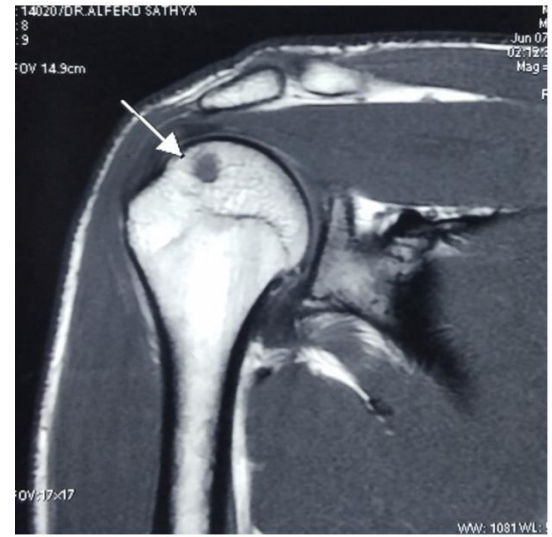

Figure 5: MRI images of Hill Sach's Lesion.

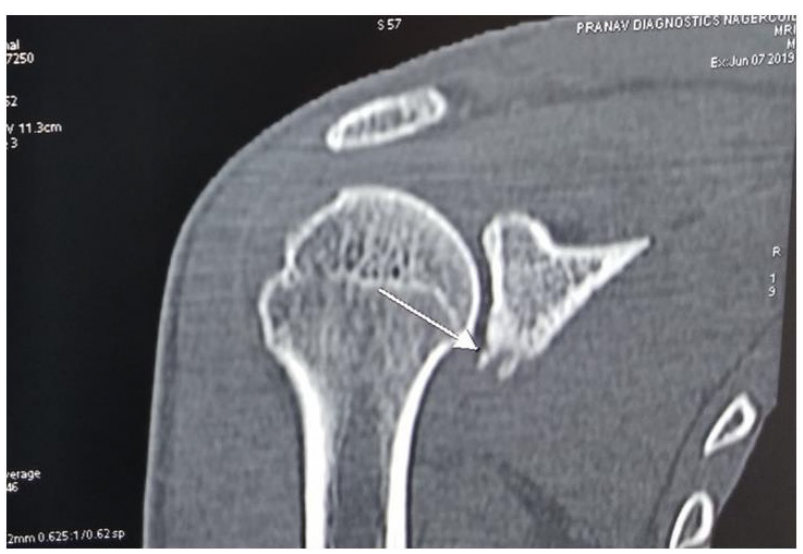

Figure 6: Bony Bankarts with Hill Sach's Lesion. 


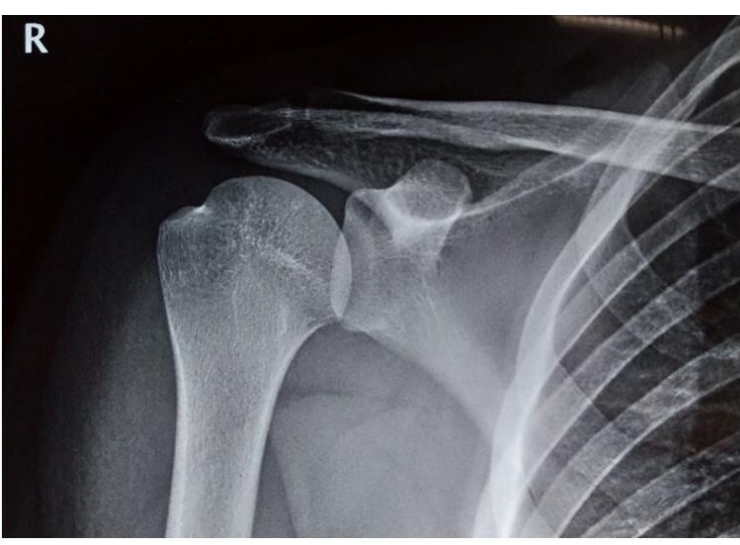

A

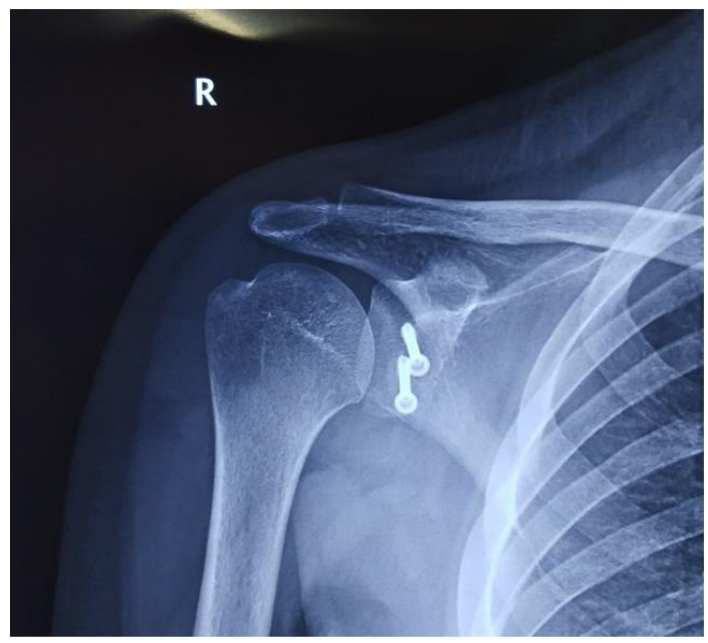

C

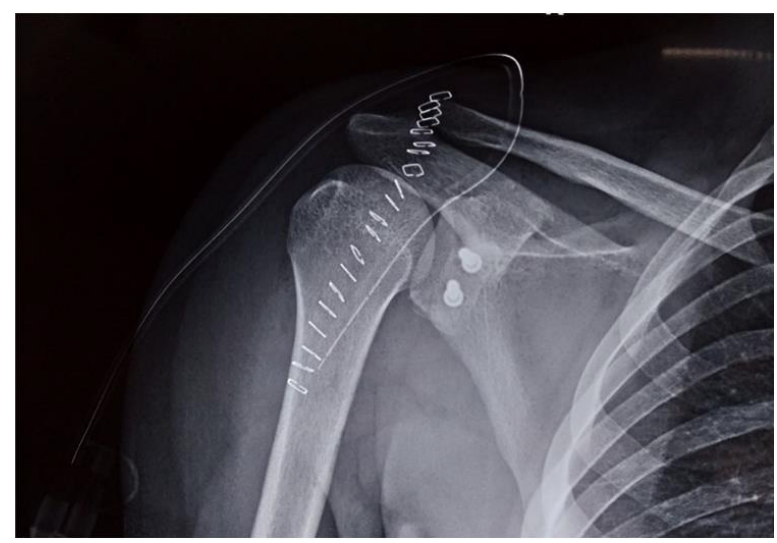

B

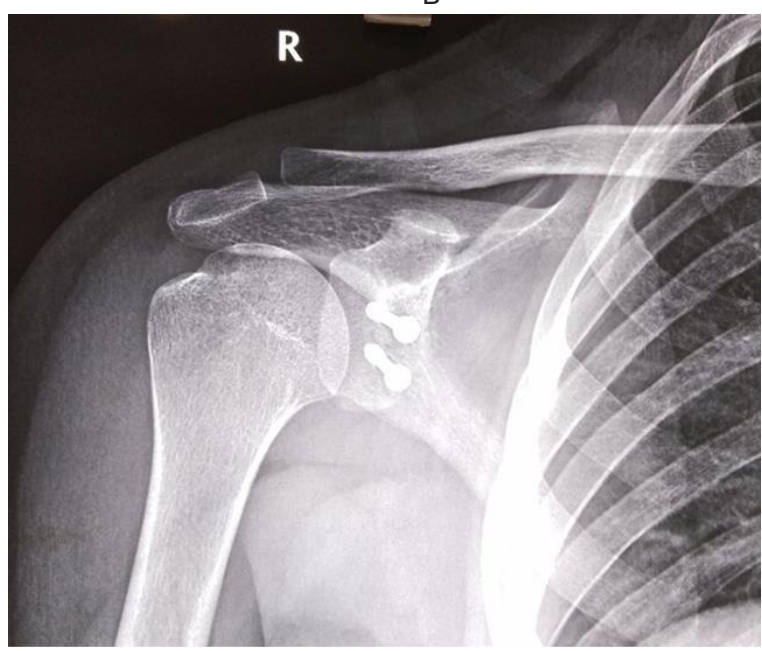

D

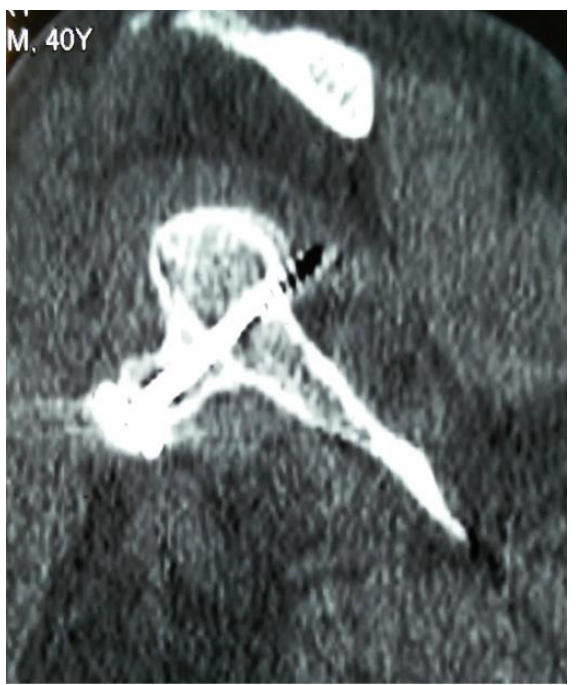

E

Figure 7: X-RAY Follow-up:

A: Preoperative $x$-ray.

B: Immediate postop $x$-ray.

C: 4 months postop x-ray.

D: Two-year follow-up x-ray.

E: CT scan showing graft union. 
Postoperatively, 5 patients (11\%) had excellent results, 34 patients $(75 \%)$ had good results, $2(4 \%)$ had fair results and 4 (9\%) had poor results as evidenced by the Rowe Score (Figure 8). 4 patients had another episode of dislocation during the follow-up period. This amounted to poor results. 8 patients (18\%) had some degree of apprehension in abducted external rotation. This included patients who had dislocated (4 patients). 10 patients (22\%) had mild pain in the shoulder. However, all patients with excellent and good results were able to perform normal daily activities, engage in manual labour and recreational sports activities. None of our patients were professional sportspersons.

\section{PIE DIAGRAM SHOWING THE OUTCOMES BASED ON ROWE SCORE}

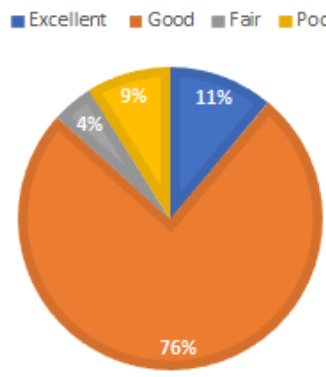

Figure 8: Pie diagram showing outcome based on Rowe Score.

There was a mean external rotation loss of 20.5 with the arm in adduction and 15.0 with arm in abduction at 90 degrees while comparing with the normal side (Figure 9 A-C). 2 patients had

Table 2: Shows the details of the study population. superficial surgical site infection which subsided without sequelae. Screw breakage occurred in one patient; however, this was not removed Table 2 .

\begin{tabular}{|c|c|}
\hline Total patients & 45 \\
\hline Male & 39 \\
\hline Females & 6 \\
\hline \multicolumn{2}{|l|}{ Age group } \\
\hline $20-30$ yrs & 32 \\
\hline $30-40$ yrs & 8 \\
\hline$>40 \mathrm{yrs}$ & 5 \\
\hline Dominant hand Right side & 45 \\
\hline \multicolumn{2}{|l|}{ Side of dislocation } \\
\hline Right & 41 \\
\hline Left & 4 \\
\hline \multicolumn{2}{|l|}{ Recurrence occurred } \\
\hline while sleeping & 6 \\
\hline while engaged in manual labour & 12 \\
\hline \multicolumn{2}{|l|}{ Number of dislocations } \\
\hline$<10$ & 30 \\
\hline$>10$ & 15 \\
\hline \multicolumn{2}{|c|}{ Associated lesions in addition to Hill Sach's } \\
\hline Soft tissue Bankart & 35 \\
\hline Bony Bankart & 4 \\
\hline Glenoid Bone Loss & 6 \\
\hline Mean preop Rowe Score & 58.5 \\
\hline \multicolumn{2}{|l|}{ Postop outcomes (Rowe Score) } \\
\hline Excellent & 5 \\
\hline Good & 34 \\
\hline
\end{tabular}




\begin{tabular}{|c|c|}
\hline Fair & 2 \\
\hline Poor & 4 \\
\hline Bony union & 38 \\
\hline Mean loss of External rotation & 15 degrees \\
\hline In abduction & 20.5 degrees \\
\hline In adduction & Oct-45 \\
\hline Pain & 1 \\
\hline Postop complications & 1 \\
\hline screw breakage & nil \\
\hline surgical site infection & nil \\
\hline axillary/suprascapular nerve palsy & \\
\hline graft osteolysis & \\
\hline
\end{tabular}

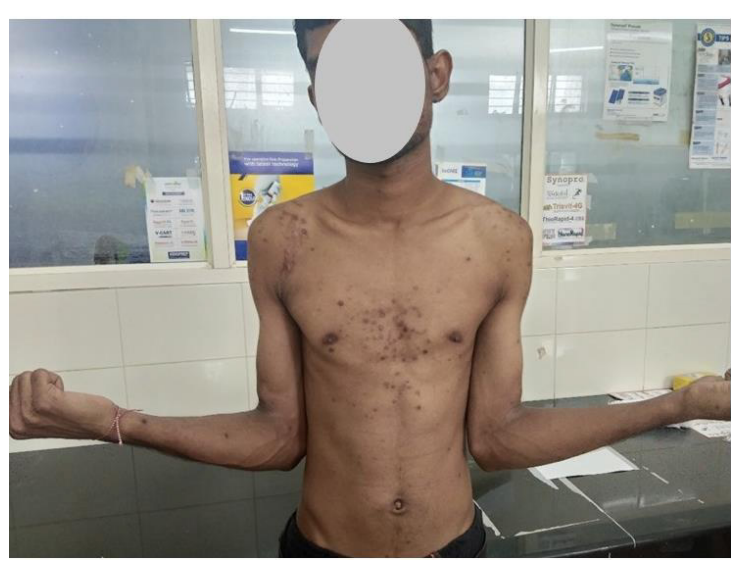

A

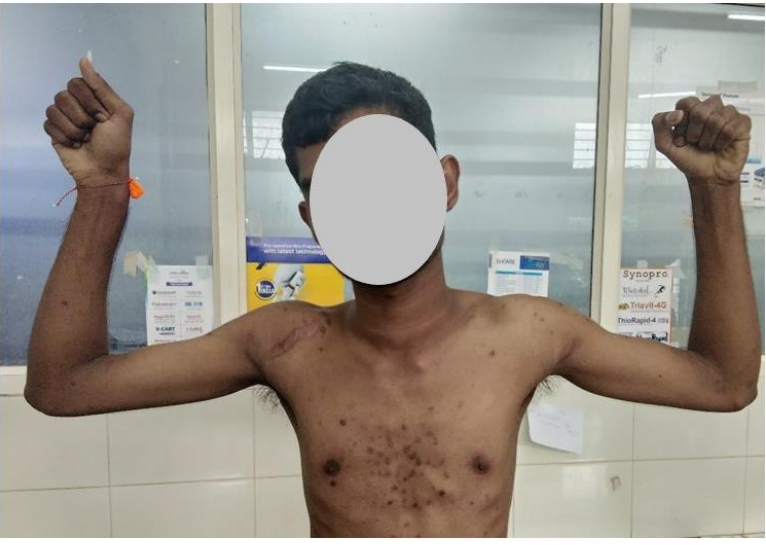

B

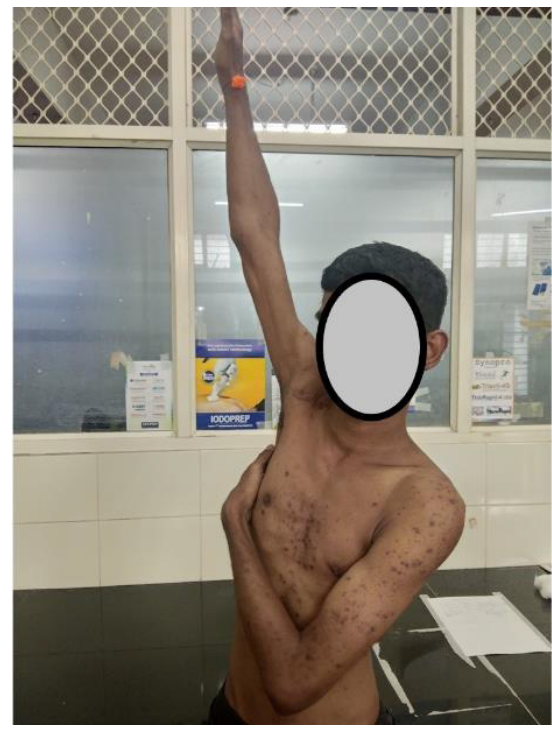

C

Figure 9: Range of movements at final follow-up (24 months).

A: ROM postop: external rotation in adduction.

B: External rotation in abduction at 24 months.

C: Abduction at 24 months.

\section{Discussion}

Recurrent anterior dislocation of the shoulder is a troublesome disorder that typically occurs in young adults. The presence of a
Bankarts capsulolabral avulsion and engaging Hill Sach's lesion are important predisposing factors for a shoulder to dislocate repeatedly [5-10] Many experts have used Bankart's (open/ arthroscopic) surgery to treat this recurrence. However, in the 
presence of an engaging Hill Sach lesion, Bankarts surgery has a higher rate of failure [22,23].

The Latarjet procedure can deal with issues occurring from either glenoid or humeral bone loss. The Latarjet procedure provides excellent functional outcome and stability in cases of recurrent anterior shoulder instability [24-30]. This bone block procedure with an osteotomized coracoid process along with conjoined tendon makes the glenoid arc congruent and covers the bone loss. It acts via three mechanisms [5,9,10,24]

- $\quad$ sling mechanism by conjoint tendon compressing subscapularis tendon and capsule

- $\quad$ glenoid rim restoration by transposed coracoid

- capsular repair using acromioclavicular ligament.

Literature $[31,32]$ considers Hill Sachs Lesion to be significant if occupying more than $25 \%$ of the humeral articular surface. However, lesions less than that can also result in recurrent dislocations depending on the pathology in the glenoid surface. To decide on whether the Hill Sach lesion is engaging or nonengaging, the concept of glenoid track $[12,13]$ has been proposed. Despite the recent studies providing data supporting the usage of the glenoid track for treatment of glenohumeral instability, there is still debate on its validity. Schneider et al [18] conducted a study using 3D CT scan images to measure the variability in glenoid track measurements. In a case study evaluating interobserver reliability, they showed that the observers struggled to come to a consensus as to if the Hill-Sachs defect was on- or off-track, with only a $72 \%$ rate of interobserver reliability. They determined the degree of variability in humeral head assessment with the glenoid was too high for the glenoid track measurement to be reliable. Due to the poor interobserver reliability, the authors recommend the avoidance of the glenoid track in preoperative assessment measures. Hence with the available evidence, it is rather difficult to ascertain preoperatively whether a Hill Sach' lesion is engaging or non-engaging. Hence there is a possibility of high rates of recurrence in the presence of Hill Sach's lesion in Bankarts surgery alone. Remplissage has been advocated to address the Hills Sach when combined with Bankarts repair. However, Purchase et al [15], Nourissat et al [33] Elkinson et al [34] and Giles et al 35 have shown that remplissage can cause significant loss of rotations in the shoulder and even stiffness in all planes of shoulder motion. Hence it is rather a difficult decision to choose the appropriate procedure in the presence of a Hill Sach's Lesion

DeBeers [36] modification of Latarjet to the Congruent arc technique helps to improve the glenoid arc area and aims to achieve a better chance for union of the graft. The performance of this procedure via a transverse split in the subscapularis helps in early rehabilitation which is key to attaining a normal range of motion of the shoulder. The traditional Latarjet technique has greater bony contact with the glenoid and greater bone width on each side of the screws compared with the congruent arc modification of the Latarjet technique. This potentially allows for a larger surface for healing in the traditional Latarjet technique. Moreover, because of the smaller width of the bone around the screw, the congruent arc modification is potentially less tolerant of screw-positioning error compared with the traditional Latarjet technique [37]. The Congruent-Arc was shown $[38,39]$ to have significantly poorer fixation stability as compared with the Classic technique but did more closely reproduce intact joint contact, which may yield more favorable long-term outcomes.

We performed the congruent arc Latarjet in patients with HSL and assessed the functional outcome with the Rowe [40] score. In our case series, 5 patients (11\%) had excellent results, 34 patients (75\%) had good results, 2 (4\%) had fair results and 4 (9\%) had poor results as evidenced by the Rowe Score. 4 patients had another episode of dislocation during the follow-up period. This amounted to poor results. 8 patients (18\%) had some degree of apprehension in abducted external rotation. This included patients who had dislocated ( 4 patients). 10 patients (22\%) had mild pain in the shoulder. 39 patients (87\%) had graft union with 6 of them having a doubtful union. However, all patients with excellent and good results were able to perform normal daily activities, engage in manual labour and recreational sports activities. None of our patients were professional sportspersons. There was a mean external rotation loss of 20.5 with the arm in adduction and 15.0 with the arm in abduction at 90 degrees while comparing with the normal side. This is similar to studies done in the Indian population by Rao [41] et al, Babu [42] et al Kakamuna [43] et al, and Pereira [44] et al by using the classic technique. Our results show that the procedure achieves satisfactory results when compared with the classic Latarjet technique as evidenced in literature. Complications like coracoid graft osteolysis [26-29,45], infection, axillary and suprascapular nerve palsy, shoulder stiffness, loss of external rotation were comparable to the published literature. The treated patients were able to return to their jobs and do recreational sports except for the patients who had redislocated.

Our study has certain limitations. It's a single-center case series and there is no head-to-head comparison between classic Latarjet / Bankarts surgery. Quantification of humeral or glenoid bone loss has not been done in our study. Our mean follow up is 2 years and only longer follow up can tell whether congruent arc Latarjet has advantages over Classic Latarjet in the development of shoulder osteoarthritis. Our study population did not have professional sportspersons, especially those in contact sports. The functional demand of these patients may be different from our study population.

However, this studied procedure is effective in giving satisfactory results in recurrent anterior dislocations. We propose this procedure in cases of associated Hill Sach's lesion, and in patients with hyperlaxity and recurring episodes by trivial trauma 
and during sleep. Careful surgical procedure and postoperative rehabilitation is essential to achieve the best outcomes.

\section{Conclusion}

Our study results show that the congruent arc Latarjet procedure with subscapularis split effectively stabilizes anterior shoulder instability in patients with Hill Sach's Lesion. It remains a viable option for treating post-traumatic anterior shoulder instability in all age groups. Various lesions like bony and soft tissue Bankart and glenoid bone loss associated with Hill-Sachs lesion can be treated successfully by this procedure. It is an effective procedure when there is an engaging Hill-Sachs lesion or glenoid bone loss of more than $25 \%$ producing recurrent anterior shoulder dislocation. There is a good graft union and satisfactory return to function. The terminal loss of external rotation observed in patients undergoing this modified Latarjet was not seen to be of clinical significance. With proper surgical technique and adequate post-operative rehabilitation, excellent functional results can be achieved.

\section{Author's Contributions}

All three others were involved in planning, treating and outcome analysis and manuscript preparation.

\section{Funding}

Nil.

\section{Conflict of Interest}

Nil.

\section{References}

1. Bankart ASB (1938) The pathology and treatment of recurrent dislocation of the shoulder joint. British Journal of Surgery.

2. Patte D, Bernageau J, Bancel P (1985) The anteroinferior vulnerable point of the glenoid rim. In: Bateman JE, Welsh RP (eds) Surgery of the shoulder. New York, Dekker: 94-99.

3. Latarjet M (1954) Treatment of recurrent dislocation of the shoulder. Lyon Chir 49(8): 994-997.

4. Latarjet M, Ricard R, Ludin P (1961) The pre-glenoid stop screw for coracoid screwing in the treatment of recurring dislocations of the shoulder. Mem Acad Chir (Paris) 87: 457- 460.

5. Ruci V, Duni A, Cake A, Ruci D, Ruci J (2015) Bristow-Latarjet Technique: Still a Very Successful Surgery for Anterior Glenohumeral Instability A Forty-Year One Clinic Experience. Open Access Maced J Med Sci 3(2): 310-314.

6. Bessiere C, Trojani C, Carles M, Mehta SS, Boileau P (2014) The open latarjet procedure is more reliable in terms of shoulder stability than arthroscopic bankart repair. Clin Orthop Relat Res 472(8): 2345-2351.

7. Rollick NC, Ono Y, Kurji HM, Nelson AA, Boorman RS, et al. (2017) Longterm outcomes of the Bankart and Latarjet repairs: a systematic review. Open Access J Sports Med 8: 97-105.

8. Blonna D, Bellato E, Caranzano F, Assom M, Rossi R, et al. (2016) Arthroscopic Bankart Repair Versus Open Bristow-Latarjet for Shoulder Instability: A Matched-Pair Multicenter Study Focused on Return to Sport. Am J Sports Med 44(12): 3198-3205.
9. Van der Linde JA, Van Wijngaarden R, Somford MP, Van Deurzen DF, Van den Bekerom MP (2016) The Bristow-Latarjet procedure, a historical note on a technique in comeback. Knee Surg Sports Traumatol Arthrosc 24(2): 470-478.

10. Joshi MA, Young AA, Balestro JC, Walch G (2013) The Latarjet-Patte procedure for recurrent anterior shoulder instabilty in contact athletes. Clin Sports Med 32(4): 731- 739.

11. Itoi E (2017) 'On-track' and 'off-track' shoulder lesions. EFORT Open Rev 2(8): 343-351.

12. Yamamoto N, Itoi E, Abe H, Minagawa H, Seki N, et al. (2007) Contact between the glenoid and the humeral head in abduction, external rotation, and horizontal extension: a new concept of glenoid track. J Shoulder Elbow Surg 16(5): 649-56.

13. Omori Y, Yamamoto N, Koishi H, Futai K, Goto A, et al. (2014) Measurement of the Glenoid Track In Vivo as Investigated by 3-Dimensional Motion Analysis Using Open MRI. Am J Sports Med 42(6): 1290-1295.

14. Hatta T, Yamamoto N, Shinagawa K, Kawakami J, Itoi E (2019) Surgical decision making based on the on-track/off-track concept for anterior shoulder instability: a case-control study. JSES Open Access 3(1): 25-28.

15. Purchase RJ, Wolf EM, Hobgood ER, Pollock ME, Smalley CC (2008) Hill-sachs "remplissage": an arthroscopic solution for the engaging HillSachs lesion. Arthroscopy 24(6): 723-726.

16. De Beer JF, Roberts C (2010) Glenoid bone defects--open latarjet with congruent arc modification. Orthop Clin North Am 41(3): 407-415

17. Armitage, MS, Elkinson, I, Giles, JW, Athwal, GS (2011) An anatomic, computed tomographic assessment of the coracoid process with special reference to the congruent-arc Latarjet procedure. Arthroscopy 27(11): $1485-1489$.

18. Schneider AK, Hoy GA, Ek ET, Andrew H Rotstein, Julie Tate, et al. (2017) Interobserver and variability of glenoid track measurements. J Shoulder Elb Surg 26(4): 573-579.

19. Shaha JS, Cook JB, Rowles DJ, Bottoni CR, Shaha SH, et al. (2016) Clinical validation of the glenoid track concept in anterior glenohumeral instability. J Bone Joint Surg Am 98(22): 1918-1923.

20. An VVG, Sivakumar BS, Phan K, Trantalis JA (2016) Systematic review and meta-analysis of clinical and patient-reported outcomes following two procedures for recurrent traumatic anterior instability of the shoulder: Latarjet procedure vs. Bankart repair. J Shoulder Elbow Surg 25(5): 853-263.

21. Elkousy H, Gartsman GM, Labriola J, O Connor DP, Edwards TB (2010) Subscapularis function following the latarjet coracoid transfer for recurrent anterior shoulder instability. Orthopedics 33(11): 802.

22. Tauber M, Resch H, Forstner R, Raffl M, Schauer J (2004) Reasons for failure after surgical repair of anterior shoulder instability. J Shoulder Elb Surg 13(3): 279-285.

23. Boileau P, Villalba M, Hery JY, Balg F, Ahrens P, et al. (2006) Risk factors for recurrence of shoulder instability after arthroscopic Bankart repair. J Bone Joint Surg Am 88(8): 1755-1763.

24. Yamamoto N, Muraki T, An KN, John W Sperling, Robert H Cofield, et al. (2013) The stabilizing mechanism of the Latarjet procedure: a cadaveric study. J Shoulder Elbow Surg 95(15): 1390-1397.

25. Young AA, Maia R, Berhouet J, Walch G (2011) Open Latarjet procedure for management of bone loss in anterior instability of the glenohumeral joint. J Shoulder Elbow Surg 20(2 Suppl): S61-S69.

26. Nourissat G, Nedellec G, O Sullivan NA, Debet-Mejean A, Dumontier C, et al. (2006) Mini-open arthroscopically assisted Bristow-Latarjet procedure for the treatment of patients with anterior shoulder instability: a cadaver study. Arthroscopy 22(10): 1113-1118. 
27. Schmid SL, Farshad M, Catanzaro S, Gerber C (2012) The Latarjet procedure for the treatment of recurrence of anterior instability of the shoulder after operative repair: a retrospective case series of forty-nine consecutive patients. J Bone Joint Surg Am 94(11): e75.

28. Bhatia S, Frank RM, Ghodadra NS, Hsu AR, Romeo AA, et al. (2014) The Outcomes and Surgical Techniques of the Latarjet Procedure. Arthroscopy 30(2): 227-235.

29. Hovelius L, Sandstrom B, Sundgren K, Saebo M (2004) One hundred eighteen Bristow-Latarjet repairs for recurrent anterior dislocation of the shoulder prospectively followed for fifteen years: study I-clinical results. J Shoulder Elbow Surg 13(5): 509-516.

30. Privitera DM, Sinz NJ, Miller LR, Siegel EJ, Solberg MJ, et al. (2018) Clinical Outcomes Following the Latarjet Procedure in Contact and Collision Athletes. J Bone Joint Surg Am 100(6): 459-465.

31. Calandra JJ, Baker CL, Uribe J (1989) The incidence of Hill-Sachs lesions in initial anterior shoulder dislocations. Arthroscopy 5(4): 254-257.

32. Kurokawa D, Yamamoto N, Nagamoto H, Yasushi Omori, Minoru Tanaka, et al. (2013) The prevalence of a large Hill-Sachs lesion that needs to be treated. J Shoulder Elb Surg 22(9): 1285-1289.

33. Nourissat G, Kilinc AS, Werther JR, Doursounian L (2011) A prospective, comparative, radiological, and clinical study of the influence of the "remplissage" procedure on shoulder range of motion after stabilization by arthroscopic Bankart repair. Am J Sports Med 39(10): 2147-2152.

34. Elkinson I, Giles JW, Faber KJ, Harm W Boons, Louis M Ferreira, et al. (2012) The effect of the remplissage procedure on shoulder stability and range of motion: an in vitro biomechanical assessment. J Bone Joint Surg Am 94(11): 1003-1012.

35. Giles JW, Elkinson I, Ferreira LM, Harm Boons, Robert Litchfield, et al. (2012) Moderate to large engaging Hill-Sachs defects: an in vitro biomechanical comparison of the remplissage procedure, allograft humeral head reconstruction, and partial resurfacing arthroplasty. J Shoulder Elb Surg 21(9): 1142-1151.

36. Burkhart SS, De Beer JF, Barth JR, Cresswell T, Roberts C, et al (2007) Results of modified Latarjet reconstruction in patients with anteroinferior instability and significant bone loss Arthroscopy 23(10): 1033-1041.
37. Dumont GD, Vopat BG, Parada S, Randy Cohn, Amun Makani, et al. (2017) Traditional Versus Congruent Arc Latarjet Technique: Effect on Surface Area for Union and Bone Width Surrounding Screws. Arthroscopy 33(5): 946-952.

38. Montgomery SR, J Christoph Katthagen, Jacob D Mikula, Daniel Cole Marchetti, Dimitri S Tahal, et al. (2017) Anatomic and Biomechanical Comparison of the Classic and Congruent-Arc Techniques of the Latarjet Procedure. The American Journal of Sports Medicine 45(6): 1252-1260.

39. Giles JW, Puskas G, Welsh M, Johnson JA, Athwal GS (2012) Do the traditional and modified latarjet techniques produce equivalent reconstruction stability and strength? Am J Sports Med 40(12): 28012807.

40. Rowe CR, Patel D, Southmayd WW (1978) The Bankart procedure: a long-term end-result study. J Bone Joint Surg Am 60(1): 1-16.

41. Rao SS, Raju SD, Chiranjeevi V (2014) Results of mini open latarjet procedure for recurrent shoulder dislocation in Indian population: A Series Of 30 Cases. IOSR J Dent Med Sci 13(11):59-62

42. Babu AS, Kumar N, MuthuS, Sukumar N (2018) Outcome analysis of management of recurrent shoulder dislocation by latarjet procedure. Int J Orthop Sci 4(1-3): 82-86.

43. PereiraJ, Ahmed AM, Kumar P, Shenoy RM (2019) Functional outcome of latarjet's procedure for recurrent shoulder dislocation. Int J Orthop Sci 5(3): 28-32.

44. Kakumanu DRK, Golla DD (2019) Analysis of the functional outcome in patients following mini-open latarjet procedure for the treatment of anterior instability of shoulder. Int J Orthop Sci 5(1): 194-199.

45. Giacomo GD, Costantini A, Gasperis N de, Vita AD, Lin BKH, et al. (2011) Coracoid graft osteolysis after the Latarjet procedure for anteroinferior shoulder instability: a computed tomography scan study of twenty-six patients. J Shoulder Elbow Surg 20(6):989-995. 